\title{
GESTÃO DE PESSOAS E SUAS PRÁTICAS NO CONTEXTO DAS PROPRIEDADES RURAIS PRODUTORAS DE GRÃOS EM MATO GROSSO
}

\author{
Nome \\ Adelice Minetto Sznitowski \\ Instituição/Afiliação \\ Universidade do Estado de Mato Grosso - UNEMAT \\ País \\ Brasil \\ Resumo da \\ Biografia \\ Adelice Minetto SznitowskiDoutora em AdministraçãoMestre em Engenharia de \\ ProduçãoProfessora adjunta na Universidade do Estado de Mato Grosso-UNEMAT \\ Contato principal para correspondência.
}

\begin{tabular}{|c|c|}
\hline Nome & Elaine Rodrigues Souza \\
\hline Instituição/Afiliação & Universidade do Estado de Mato Grosso-UNEMAT \\
\hline País & Brasil \\
\hline $\begin{array}{l}\text { Resumo da } \\
\text { Biografia }\end{array}$ & $\begin{array}{l}\text { Mestre em Engenharia de ProduçãoProfessora na } L \\
\text { Grosso-UNEMAT }\end{array}$ \\
\hline Nome & Angélica Aparecida Batista Suquere \\
\hline Instituição/Afiliação & Universidade do Estado de Mato Grosso-UNEMAT \\
\hline País & Brasil \\
\hline $\begin{array}{l}\text { Resumo da } \\
\text { Biografia }\end{array}$ & $\begin{array}{l}\text { Acadêmica do Curso de Administração da } \\
\text { Universidade do Estado de Mato Grosso-UNEMAT }\end{array}$ \\
\hline Nome & Carolina Mendes do Nascimento \\
\hline Instituição/Afiliação & Universidade do Estado de Mato Grosso-UNEMAT \\
\hline País & - \\
\hline $\begin{array}{l}\text { Resumo da } \\
\text { Biografia }\end{array}$ & $\begin{array}{l}\text { Acadêmica do Curso de Administração da } \\
\text { Universidade do Estado de Mato Grosso-UNEMAT }\end{array}$ \\
\hline
\end{tabular}

\section{RESUMO}

Gestão de pessoas é a função que se refere ao gerenciamento de pessoas e a atribuição de tarefas numa organização e para tanto, compreende um conjunto de práticas que objetivam adequação dos indivíduos ao ambiente de trabalho para a realização das atividades ao longo do tempo. Perante a carência de estudos sobre práticas gestão de pessoas em propriedades rurais, entendeu-se como pertinente investigá-las nesse contexto. Com essa perspectiva, objetivou-se identificar as práticas de gestão de pessoas adotadas nas propriedades rurais produtoras de grãos no Núcleo Oeste em Mato Grosso. O estudo baseado em dados qualitativos coletados em sete propriedades rurais de médio e grande porte por meio de entrevista semiestruturada elaborada a partir de categorias de análise extraídas da literatura sobre o tema. Assumiu-se então que, gerir pessoas compreende seis processos: agregar pessoas, aplicar pessoas, recompensar pessoas, desenvolver pessoas, manter pessoas e monitorar pessoas. Os resultados obtidos revelam que todos os locais analisados adotam práticas de gestão de pessoas, porém não em sua totalidade e de forma limitada e nem todos os produtores rurais percebem as práticas dessa área como importantes. Diante dessa realidade, sugere-se maior atenção a essa temática a qual afeta diretamente o desempenho e resultados organizacionais. 
Palavras-chave: Gestão de pessoas. Práticas. Empreendimentos rurais. Gestão de propriedades Rurais.

\section{INTRODUÇÃO}

O agronegócio é destaque na economia do Brasil. A safra brasileira de grãos em 2017 avançou em 21,8\% em relação a 2016, passando de 184 milhões para 224,2 milhões de toneladas, contribuindo substancialmente para o crescimento do Produto Interno Bruto (PIB). O PIB do agronegócio brasileiro cresceu 4,48\% em 2016 e entre janeiro e dezembro 5,77\%, superando a expectativa do setor (REUTERS, 2017).

O desempenho do agronegócio resulta do aumento da produção agropecuária do país, e também da competitividade do setor decorrente dos avanços da tecnologia para o desenvolvimento das culturas e manejo das lavouras (CALLADO, 2011).

Como resultado dessa representatividade, o agronegócio torna-se um dos setores importantes para a economia brasileira, trazendo avanços quantitativos e qualitativos pela capacidade de gerar renda e empregos. Nesse sentido, Araújo (2005) destaca que entre os dez segmentos econômicos que geram empregos, sete são do agronegócio.

Trata-se de um setor amplo, pois envolve o conjunto de todas as operações desde a fabricação dos insumos agropecuários, das operações de produção nas unidades agropecuárias, até o processamento, distribuição e consumo dos produtos agropecuários in natura ou industrializados (ARAÚJO, 2005).

Embora o agronegócio brasileiro seja um setor expressivo para a economia do país, as unidades de produção agropecuária ainda carecem de estudos focados na gestão. Poucas investigações abordam as práticas de gestão dos agricultores (aspectos internos) e como esse gerenciamento impacta o desempenho do empreendimento rural (GRAY; PARKER; KEMP, 2009). A maioria aborda fatores externos e não as unidades produtivas (ARAÚJO, 2005).

Dentre as práticas de gestão, uma delas é a gestão de pessoas, área essa de importância para o desenvolvimento de um empreendimento, uma vez que, por meio dela, é possível a captar, capacitar, envolver e desenvolver pessoas na perspectiva de parceiros do negócio (FRANÇA, 2011).

$\mathrm{Na}$ empresa rural, as atividades desenvolvidas pela área de gestão de pessoas são fundamentais, dai a necessidade do uso de técnicas para melhorar essa área (CAIRES, 2017). No entanto, essa área e suas práticas demandam maior atenção por parte dos gestores dos empreendimentos rurais, como constatado por Sznitowski (2017). Soma-se a isso, o estudo realizado por Leitner (2015) nas propriedades rurais do Núcleo Oeste de Mato Grosso, segundo 
classificação da Associação dos Produtores de Soja do Estado de Mato Grosso (APROSOJA), evidenciando que em alguns locais eram desenvolvidas práticas na área de gestão de pessoas, porém não foram citadas quais. Diante do exposto, a proposta desse estudo consiste em identificar as práticas de gestão de pessoas adotadas nas propriedades produtoras de grãos no Núcleo Oeste em Mato Grosso, Estado esse que ocupa o primeiro lugar na produção de grãos de acordo com o Instituto Matogrossense de Economia e Agropecuária (IMEA, 2017).

Diante da perspectiva central do estudo, foram descritas as práticas de gestão de pessoas utilizadas nas propriedades rurais, elencadas as práticas com dificuldades em sua adoção e, identificada a percepção dos produtores rurais quanto à importância das referidas práticas.

O artigo está estruturado da seguinte forma: nesta introdução tem-se a justificativa bem como os objetivos para realização deste estudo; na sequência apresenta-se o método adotado; no tópico seguinte está a revisão dos conceitos chaves para a compreensão do assunto, trazendo as práticas de gestão de pessoas baseada nos principais autores da área e, a seguir a análise e discussão dos dados a luz do embasamento teórico, culminando com as considerações finais.

\section{REFERENCIAL TEÓRICO 2.1 Gestão de Pessoas e seus Processos}

Para Gil (2010, p 17), “gestão de pessoas é a função gerencial que visa à cooperação das pessoas que atuam nas organizações para o alcance dos objetivos tanto organizacionais quanto individuais". Envolve o modo de gerenciar as pessoas numa organização e atribuir tarefas a elas (PIZOLOTTO; DREWS, 2009) e compreende uma gama de atividades, como recrutamento e seleção, descrição de cargos, treinamento e desenvolvimento, avaliação de desempenho, dentre outras (GIL, 2010). Nesse sentido, Chiavenato (2010) cita os seis processos básicos de gestão de pessoas (GP) e suas práticas as quais são mostradas no Quadro 01.

Quadro 1- Gestão de Pessoas e os Processos

\begin{tabular}{|c|c|c|c|c|c|}
\hline \multicolumn{6}{|c|}{ GESTÃO DE PESSOAS } \\
\hline $\begin{array}{c}\text { Processos de } \\
\text { agregar } \\
\text { pessoas } \\
\end{array}$ & $\begin{array}{c}\text { Processos de } \\
\text { aplicar pessoas }\end{array}$ & $\begin{array}{c}\text { Processos de } \\
\text { recompensar } \\
\text { pessoas } \\
\end{array}$ & $\begin{array}{c}\text { Processos de } \\
\text { desenvolver } \\
\text { pessoas } \\
\end{array}$ & $\begin{array}{c}\text { Processos de } \\
\text { manter } \\
\text { pessoas } \\
\end{array}$ & $\begin{array}{c}\text { Processos de } \\
\text { monitorar } \\
\text { pessoas }\end{array}$ \\
\hline $\begin{array}{l}\text { São os } \\
\text { processos } \\
\text { utilizados } \\
\text { para incluir } \\
\text { novas pessoas } \\
\text { na } \\
\text { organização. }\end{array}$ & \begin{tabular}{lr}
\multicolumn{2}{l}{ São os processos } \\
utilizados para \\
desenhar as \\
atividades que as \\
pessoas irão \\
realizar na \\
empresa, orientar \\
e acompanhar \\
seu desempenho
\end{tabular} & $\begin{array}{l}\text { São os processos } \\
\text { utilizados para } \\
\text { incentivar as } \\
\text { pessoas } \\
\text { satisfazer suas } \\
\text { necessidades } \\
\text { individuais mais } \\
\text { elevadas. }\end{array}$ & \begin{tabular}{lr}
\multicolumn{2}{c}{ São os processos } \\
utilizados para \\
capacitar \\
incrementar & $\mathrm{e}$ \\
desenvolvimento \\
profissional \\
pessoal \\
pessoas
\end{tabular} & $\begin{array}{l}\text { São os } \\
\text { processos } \\
\text { utilizados } \\
\text { para criar } \\
\text { condições } \\
\text { ambientais e } \\
\text { psicológicos } \\
\text { satisfatórios } \\
\text { para as } \\
\text { atividades das } \\
\text { pessoas. }\end{array}$ & $\begin{array}{l}\text { São os } \\
\text { processos } \\
\text { utilizados } \\
\text { para } \\
\text { acompanhar e } \\
\text { controlar as } \\
\text { atividades das } \\
\text { pessoas e } \\
\text { verificar } \\
\text { resultados. }\end{array}$ \\
\hline
\end{tabular}




\begin{tabular}{|l|l|l|l|l|l|}
\hline \multicolumn{1}{|c|}{ Incluem } & \multicolumn{1}{|c|}{ Incluem } & \multicolumn{1}{|c|}{ Incluem } & Incluem & Incluem & \multicolumn{1}{|c|}{ Incluem } \\
\hline $\begin{array}{l}\text { Recrutamento } \\
\text { Seleção }\end{array}$ & Descrição de & Remuneração & Treinamento & Qualidade & Banco de \\
& $\begin{array}{l}\text { cargos } \\
\text { Avaliação } \\
\text { de desempenho }\end{array}$ & Incentivos & Desenvolvícios & de carreira & de vida \\
no trabalho & $\begin{array}{l}\text { Sistema de } \\
\text { informações } \\
\text { gerenciais }\end{array}$ \\
\hline
\end{tabular}

Fonte: Adaptado de Chiavenato (2010).

Todos esses seis processos estão relacionados entre si e podem favorecer ou prejudicar os demais, quando bem ou mal utilizados. Buscar o equilíbrio entre todos é fundamental (MARRAS, 2005).

O uso de ferramentas no processo de gestão de pessoas de forma integrada e direcionadas para as diversas funções realizadas contribui para maior efetividade e consequentemente melhores resultados organizacionais. Diante disso é importante conhecer os processos e suas práticas (CODA, 2016; GRAMIGNA, 2017; PEREIRA, 2014).

Dentre os seis processos citados no quadro 1, o primeiro envolve agregar pessoas com práticas de recrutamentos e seleção. Recrutamento de pessoas permite que organizações atraiam profissionais qualificados para o desempenho de suas funções. Essa captação de capital humano pode ser interna ou externa e fornece base para a próxima etapa que é a seleção de pessoas. Selecionar pessoas tem por finalidade escolher os candidatos com competências que atendam as necessidades internas da empresa (MARRAS, 2005; PEREIRA, 2014).

O segundo processo se refere a aplicar pessoas e tem como práticas a descrição de cargos e avaliação de desempenho. A descrição de cargos fornece informações globais do cargo de forma organizada e padronizada em relação às atividades que compõe o cargo (GIL, 2010). Já a avaliação de desempenho permite ao gestor medir os resultados alcançados pelos funcionários em um determinado período de tempo e área específica, relacionando suas competências pessoais com as exigidas pelo cargo, as quais envolvem conhecimentos, habilidades e atitudes adquiridas e em desenvolvimento, possibilitando projeção futura de carreira profissional (MARRAS, 2005; CODA, 2016).

O processo de recompensar, terceiro a ser mencionado, diz respeito as práticas como remuneração, incentivos e benefícios ofertados. Além da remuneração que a organização pode oferecer para estimular seus funcionários, existem ainda os programas de incentivos que contribuem para incentivar a melhora de desempenho. Tais incentivos devem ser vinculados ao processo de execução de estratégias e resultados a serem concretizados, tanto de forma individual ou grupal. Já os benefícios são programas ou planos oferecidos pelas organizações como complementação ao salário com o objetivo de propiciar facilidades sociais, educacionais 
e recreativas, promovendo com isso o bem estar para aqueles que os acessam (MARRAS, 2005; BOHLANDER E SNELL, 2010).

O quarto processo é desenvolver pessoas e se dá por meio de práticas como treinamento e desenvolvimento de carreira. Treinamento é um processo sistemático para promover a aquisição de habilidades, conceitos e atitudes para melhor adequação entre as características dos funcionários e as exigências dos papéis a serem desempenhados, direciona a geração de oportunidades para a melhoria das competências essenciais para o trabalho eficiente, as quais passam a ser diagnosticadas pela avaliação de desempenho, seja individual ou grupal (FRANÇA, 2011; PEREIRA, 2014). Já o desenvolvimento humano se refere a capacidade para assumir atribuições e responsabilidades em níveis crescentes de complexidade, ou seja, preparar as pessoas para um contexto cada vez mais exigente e complexo por meio de instruções quanto ao autodesenvolvimento profissional (DUTRA, 2002; CODA, 2016).

O processo manter pessoas, o quinto deles, versa sobre práticas de qualidade de vida no trabalho. Tais ações visam um ambiente de trabalho mais humanizado, com a demonstração constante da preocupação da empresa no que tange ao bem estar geral, investindo em diversos aspectos que influenciam na valorização e reconhecimento de seus profissionais, tais como remuneração justa, oportunidades de carreira, segurança e confiança na gestão, orgulho do trabalho e da empresa, clareza e abertura na comunicação. Essas ações refletem positivamente nos desempenho empresarial (GIL, 2010; PEREIRA, 2014).

O sexto e último processo a ser destacado diz respeito a monitorar pessoas e compreende banco de dados e sistema de informação em gestão de pessoas. O banco de dados funciona como um sistema de armazenamento de dados de cada indivíduo no seu contexto do trabalho. Já o sistema de informação se destina ao processamento de informações que servem de base para o processo decisório em relação ao desenvolvimento da carreira de todos os funcionários, indicando assim as necessidades e as oportunidades que devem ser direcionadas para promover a geração de competências essenciais ao desenvolvimento organizacional. Assim como também pode possibilitar a cada funcionário o próprio acesso a informações de seu trabalho, o que possibilita o autodesenvolvimento (CHIAVENATO, 2010).

No agronegócio como nos demais setores, as pessoas são parte fundamental no âmbito da produção e responsáveis por atender as necessidades organizacionais quanto as tarefas e funções exigidas (AMORIM, 2011). 
Nas propriedades rurais Kay et.al. (2014) citam que a mão de obra é um dos recursos que tem seu uso quantitativo reduzido em função da tecnologia incorporada nas máquinas. Contudo, a introdução das tecnologias poupadoras de mão de obra permitiu que a produção agropecuária crescesse, e esse aumento da produtividade por meio da utilização da tecnologia possibilitou que os proprietários rurais desfrutassem de um padrão de vida compatível com a da população urbana.

Gerir as pessoas que trabalham no âmbito do agronegócio envolve atividades como a busca por profissionais qualificados para desempenhar as tarefas exigidas diante da dificuldade de conseguir pessoas qualificadas para atender a demanda (AMORIM, 2011).

Dai a pertinência em abordar o tema gestão de pessoas no agronegócio no contexto das unidades de produção para com isso contribuir com os gestores do meio rural quanto à adoção de práticas da área de gestão de pessoas para aumentar potencial produtivo do capital humano.

\section{METODOLOGIA}

O estudo baseado em dados qualitativos se caracterizou como exploratório por abordar um tema pouco discutido aos moldes propostos (HUSSEY; COLLIS, 2005). Os meios utilizados para sua realização envolveram pesquisa de campo com aplicação de entrevista semiestruturada contendo no primeiro bloco indagações para caracterizar o empreendimento rural e no segundo bloco questões sobre as práticas de gestão de pessoas adotadas, práticas essas elencadas a partir de autores clássicos da área de gestão de pessoas como mostrado no quadro 2, as quais compreendem seis processos: processos de agregar pessoas, aplicar pessoas, recompensar pessoas, desenvolver pessoas, de manter pessoas e monitorar pessoas.

Quadro 2- Categorias de análise adotadas para identificar as práticas de gestão de pessoas

\begin{tabular}{|c|c|c|}
\hline $\begin{array}{c}\text { Processo de agregar } \\
\text { pessoas }\end{array}$ & $\begin{array}{ll}\text { - } & \text { Recrutamento } \\
\text { - } & \text { Seleção }\end{array}$ & $\begin{array}{l}\text { Xavier (2006). } \\
\text { Marra (2000). } \\
\text { Chiavenato (2004), (2010). } \\
\text { França (2011). } \\
\text { Pereira (2014). }\end{array}$ \\
\hline $\begin{array}{c}\text { Processo de aplicar } \\
\text { pessoas }\end{array}$ & $\begin{array}{l}\text { - } \quad \text { Descrição de cargo } \\
\text { - } \quad \text { Avaliação de desempenho }\end{array}$ & $\begin{array}{l}\text { Bohlander e Snell (2010). } \\
\text { França (2011). } \\
\text { Chiavenato (2010), (2014). } \\
\text { Caxito (2012). } \\
\text { Gil (2010). } \\
\text { Coda (2016). }\end{array}$ \\
\hline $\begin{array}{l}\text { Processo de } \\
\text { recompensar pessoas }\end{array}$ & $\begin{array}{ll}\text { - } & \text { Renumeração } \\
\text { - } & \text { Incentivos } \\
\text { - } & \text { Benefícios }\end{array}$ & $\begin{array}{l}\text { Chiavenato (2004), } \\
(2009),(2010),(2014) . \\
\text { Gil (2010). } \\
\text { Bohlander e Snell (2010). }\end{array}$ \\
\hline
\end{tabular}




\begin{tabular}{|c|c|c|}
\hline & & $\begin{array}{l}\text { Marras (2005). } \\
\text { Desseler (2003). } \\
\text { Franco (2011). } \\
\text { Pereira (2014). }\end{array}$ \\
\hline $\begin{array}{l}\text { Processo de desenvolver } \\
\text { pessoas }\end{array}$ & $\begin{array}{l}\text { - } \quad \text { Treinamento } \\
\text { Desenvolvimento de } \\
\text { carreira }\end{array}$ & $\begin{array}{l}\text { Gil (2010). } \\
\text { França (2011). } \\
\text { Chiavenato (2010) } \\
\text { Ribeiro (2000) } \\
\text { Richel (2008) } \\
\text { Dutra (2002) } \\
\text { Coda (2016). }\end{array}$ \\
\hline $\begin{array}{c}\text { Processo de manter } \\
\text { pessoas }\end{array}$ & $\begin{array}{l}\text { Qualidade de vida no } \\
\text { trabalho }\end{array}$ & $\begin{array}{l}\text { Gil (2010). } \\
\text { Chiavento (2010), (2014). } \\
\text { Pereira (2014). }\end{array}$ \\
\hline $\begin{array}{c}\text { Processo de monitorar } \\
\text { pessoas }\end{array}$ & $\begin{array}{ll}- & \text { Bancos de dados } \\
\text { - } & \text { Sistema de informações } \\
\text { gerenciais }\end{array}$ & $\begin{array}{l}\text { Chiavenato (2010), (2014). } \\
\text { Pina e Santos (2000). } \\
\text { Leitner (2015). }\end{array}$ \\
\hline
\end{tabular}

Fonte: Elaborado pelos autores (2017)

Foram entrevistados sete empreendedores rurais de propriedades produtoras de grãos no Núcleo Oeste da APROSOJA localizadas no município de Campo Novo do Parecis-MT, entre os meses de agosto a outubro de 2017.

\section{APRESENTAÇÃO E ANÁLISE DE RESULTADOS}

\subsection{Caracterização das propriedades rurais}

O principal produto cultivado nas sete propriedades rurais é a soja, soja e milho e uma delas faz integração pecuária-floresta e agricultura-pecuária. No quadro 3 podem ser observadas as demais particularidades dos empreendimentos analisados, os quais se enquadram como de médio e grande porte.

Quadro 03 - Caracterização das propriedades rurais de Campos Novo do Parecis-MT em 2017

\begin{tabular}{|c|c|c|c|c|}
\hline Propriedades & Localização & $\begin{array}{c}\text { Número de } \\
\text { funcionários fixos }\end{array}$ & $\begin{array}{c}\text { Números de } \\
\text { funcionários } \\
\text { contratados no período } \\
\text { da safra }\end{array}$ & $\begin{array}{c}\text { Área em } \\
\text { hectares * }\end{array}$ \\
\hline $\mathbf{A}$ & $\begin{array}{c}\text { Campo Novo do } \\
\text { Parecis }\end{array}$ & 17 & 5 & 2.000 \\
\hline $\mathbf{B}$ & $\begin{array}{c}\text { Campo Novo do } \\
\text { Parecis }\end{array}$ & 8 & 18 & 450 \\
\hline $\mathbf{C}$ & $\begin{array}{c}\text { Campo Novo do } \\
\text { Parecis }\end{array}$ & 39 & 0 & 5.589 \\
\hline $\mathbf{E}$ & $\begin{array}{c}\text { Campo Novo do } \\
\text { Parecis }\end{array}$ & 9 a 12 & 6 & 5.100 \\
\hline
\end{tabular}




\begin{tabular}{|c|c|c|c|c|}
\hline $\mathbf{F}$ & $\begin{array}{c}\text { Campo Novo do } \\
\text { Parecis }\end{array}$ & 10 & 0 & 5.100 \\
\hline $\mathbf{G}$ & $\begin{array}{c}\text { Campo Novo do } \\
\text { Parecis }\end{array}$ & 18 & 5 & 6.700 \\
\hline
\end{tabular}

Fonte: dados da pesquisa (2017).

*A Lei nº 8.629/1993 (Art. 4, II e III) classifica pequena propriedade (imóvel com área entre 1 e 4 módulos fiscais - no MT corresponde de 100 a 400ha ) e média propriedade (área superior a 4 e até 15 módulos fiscais- no MT corresponde de 400 a $1.500 \mathrm{ha}$ ) e a grande propriedade aquela com área superior a 15 módulos fiscais (no MT acima de 1500ha).

Pode-se observar que dentre as propriedades rurais, a $\mathrm{C}$ tem maior número funcionários fixos em função de cultivar mais de um tipo de produto. Das sete propriedades rurais, maior parte delas (a A, B, E e G) trabalha com mão de obra temporária contratada no período da safra. Embora a propriedade B seja a que tem menor área (450 ha) é a que mais contrata funcionários no período da safra (53 pessoas).

\subsection{Práticas de gestão de pessoas utilizadas nas propriedades rurais}

Práticas adequadas de gestão de pessoas faz com que as organizações reconheçam seus funcionários como fonte do seu sucesso, uma vez que as pessoas podem potencializar ou reduzir as forças e fraquezas da empresa dependendo da maneira como são tratadas. Podem ser fonte de sucesso ou fonte de problemas, por isso é melhor percebê-las como fonte de sucesso e desenvolvê-las alinhadas com as competências essenciais para o modelo de negócio praticado (CHIAVENATO, 2010; CODA, 2016; FERNANDES, 2013; GRAMIGNA, 2017; PEREIRA, 2014). Nesse sentido nota-se que se as práticas de gestão de pessoas forem adequadamente aplicadas geram resultados positivos no desempenho organizacional, tanto em empreendimentos tradicionais como nos rurais que ganham destaque em crescimento em relação aos outros setores.

Como já fora mencionado, a gestão de pessoas é um conjunto integrado de processos dinâmicos e interativos. Esse processo no âmbito das propriedades rurais é apresentado no quadro 4 o qual destaca as práticas de gestão de pessoas utilizadas ou não por elas.

Quadro 4- Práticas de gestão de pessoas utilizadas nas propriedades rurais

\begin{tabular}{|c|c|c|c|c|c|c|c|}
\hline & \multicolumn{7}{|c|}{ PROPRIEDADES } \\
PRÁTICAS DE \\
$\begin{array}{c}\text { GESTÃO DE } \\
\text { PESSOAS }\end{array}$ & A & B & C & D & E & F & G \\
\hline Recrutamento & Sim & Sim & Sim & Sim & Sim & Sim & Sim \\
\hline
\end{tabular}




\begin{tabular}{|c|c|c|c|c|c|c|c|}
\hline $\begin{array}{c}\text { Como divulgam } \\
\text { as vagas }\end{array}$ & $\begin{array}{l}\text { Boca em } \\
\text { boca } \\
\text { SINE e } \\
\text { Outros }\end{array}$ & $\begin{array}{c}\text { Boca em } \\
\text { boca e } \\
\text { Outros }\end{array}$ & $\begin{array}{c}\text { Boca em } \\
\text { boca } \\
\text { SINE e } \\
\text { Agência de } \\
\text { emprego }\end{array}$ & $\begin{array}{l}\text { Manual da } \\
\text { fazenda } \\
\text { SINE }\end{array}$ & $\begin{array}{l}\text { Boca em } \\
\text { boca } \\
\text { Agência de } \\
\text { emprego }\end{array}$ & $\begin{array}{l}\text { Mural da } \\
\text { fazenda }\end{array}$ & $\begin{array}{l}\text { Boca em } \\
\text { boca } \\
\text { Agência de } \\
\text { empregos }\end{array}$ \\
\hline Seleção & Não & Sim & Sim & Sim & Sim & Sim & Sim \\
\hline Técnica utilizada & Entrevista & Entrevista & Entrevista & Entrevista & Entrevista & Entrevista & Entrevista \\
\hline $\begin{array}{c}\text { Descrição de } \\
\text { cargos }\end{array}$ & Não & Sim & Sim & Não & Sim & Sim & Sim \\
\hline $\begin{array}{l}\text { Os funcionários } \\
\text { conhecem suas } \\
\text { funções }\end{array}$ & Sim & Sim & Sim & Sim & Sim & Sim & Sim \\
\hline $\begin{array}{l}\text { Avaliação de } \\
\text { desempenho }\end{array}$ & Não & Sim & Sim & Não & Sim & Sim & Sim \\
\hline Remuneração & $\begin{array}{c}\text { Salário } \\
\text { fixo e entre } \\
\text { outros }\end{array}$ & $\begin{array}{c}\text { Salário } \\
\text { fixo e entre } \\
\text { outros } \\
\end{array}$ & $\begin{array}{c}\text { Salário } \\
\text { fixo e entre } \\
\text { outros }\end{array}$ & $\begin{array}{c}\text { Salário } \\
\text { fixo e entre } \\
\text { outros } \\
\end{array}$ & $\begin{array}{c}\text { Salário } \\
\text { fixo e entre } \\
\text { outros }\end{array}$ & $\begin{array}{c}\text { Salário } \\
\text { fixo e entre } \\
\text { outros }\end{array}$ & $\begin{array}{c}\text { Salário } \\
\text { fixo e entre } \\
\text { outros }\end{array}$ \\
\hline Incentivos & $\begin{array}{c}\text { Bônus } \\
\text { anual }\end{array}$ & $\begin{array}{c}\begin{array}{c}\text { Bônus } \\
\text { anual }\end{array} \\
\end{array}$ & $\begin{array}{c}\text { Bônus } \\
\text { anual }\end{array}$ & $\begin{array}{c}\begin{array}{c}\text { Bônus } \\
\text { anual }\end{array} \\
\end{array}$ & $\begin{array}{c}\text { Bônus } \\
\text { anual }\end{array}$ & $\begin{array}{c}\text { Bônus } \\
\text { anual }\end{array}$ & $\begin{array}{c}\begin{array}{c}\text { Bônus } \\
\text { anual }\end{array} \\
\end{array}$ \\
\hline Benefícios & $\begin{array}{l}\text { Plano de } \\
\text { saúde, } \\
\text { transporte }\end{array}$ & $\begin{array}{l}\text { Plano de } \\
\text { saúde, } \\
\text { transporte }\end{array}$ & $\begin{array}{l}\text { Plano de } \\
\text { saúde, } \\
\text { transporte }\end{array}$ & $\begin{array}{l}\text { Plano de } \\
\text { saúde, } \\
\text { transporte }\end{array}$ & $\begin{array}{l}\text { Plano de } \\
\text { saúde, } \\
\text { transporte }\end{array}$ & $\begin{array}{l}\text { Plano de } \\
\text { saúde, } \\
\text { transporte }\end{array}$ & $\begin{array}{l}\text { Plano de } \\
\text { saúde. }\end{array}$ \\
\hline Treinamento & Sim & Sim & Sim & Sim & Sim & Sim & Sim \\
\hline $\begin{array}{l}\text { Desenvolvimento } \\
\text { de carreiras }\end{array}$ & Não & Sim & Sim & Sim & Sim & Não & Não \\
\hline $\begin{array}{c}\text { Qualidade de } \\
\text { vida }\end{array}$ & Sim & Sim & Sim & Sim & Sim & Sim & Sim \\
\hline $\begin{array}{l}\text { Técnicas } \\
\text { utilizadas }\end{array}$ & $\begin{array}{l}\text { EPIs, } \\
\text { remune- } \\
\text { ração justa, } \\
\text { etc. }\end{array}$ & $\begin{array}{l}\text { EPIs, } \\
\text { remune- } \\
\text { ração justa, } \\
\text { etc. }\end{array}$ & $\begin{array}{l}\text { EPIs, } \\
\text { remune- } \\
\text { ração justa, } \\
\text { etc. }\end{array}$ & $\begin{array}{l}\text { EPIs, } \\
\text { remune- } \\
\text { ração justa, } \\
\text { etc. }\end{array}$ & $\begin{array}{l}\text { EPIs, } \\
\text { remune- } \\
\text { ração justa, } \\
\text { etc. }\end{array}$ & $\begin{array}{l}\text { EPIs, } \\
\text { remune- } \\
\text { ração justa, } \\
\text { etc. }\end{array}$ & $\begin{array}{l}\text { EPIs, } \\
\text { remune- } \\
\text { ração justa, } \\
\text { etc. }\end{array}$ \\
\hline Banco de dados & Não & Sim & Sim & $\mathrm{NR}^{*}$ & Sim & Não & Sim \\
\hline $\begin{array}{c}\text { Sistema de } \\
\text { informação } \\
\text { gerencial }\end{array}$ & Não & Sim & Sim & $\mathrm{NR}^{*}$ & Não & Sim & Sim \\
\hline
\end{tabular}

Fonte: dados da pesquisa (2017).

*Não respondeu

Percebe-se no quadro 4 que algumas práticas de gestão de pessoas não são adotadas, como é o caso das técnicas de seleção, descrição de cargos, avaliação de desempenho, incentivos, banco de dados e sistema de informação, práticas essas a serem discutidas no próximo tópico.

\subsection{Práticas com dificuldades de adoção pelas propriedades rurais}

A análise dos dados coletados juntos as propriedades rurais apontam as práticas de gestão de pessoas que precisam de atenção. A não adoção dessas por parte dos produtores, foi 


\section{Contabilidade}

atribuída à dificuldade de mensurar os resultados, falta de tempo para desenvolver tais ferramentas ou por não ter um funcionário destinado a realizar essas atividades.

O quadro 05 apresenta as práticas de gestão de pessoas que podem ser melhoradas e/ou implantadas no contexto analisado, pois mesmos sendo adotadas, apresentam certa dificuldade em sua execução. Assim, pontuam-se seis práticas marcadas com " $\mathrm{X}$ " para as quais possuem maiores dificuldades em adotar.

Quadro 5- Práticas citadas pelas propriedades rurais com maiores dificuldades

\begin{tabular}{|c|c|c|c|c|c|c|c|}
\multicolumn{1}{c|}{} & \multicolumn{7}{c|}{ PROPRIEDADES } \\
\hline PRÁTICAS & A & B & C & D & E & F & G \\
\hline Recrutamento & - & - & - & - & - & - & - \\
\hline Seleção & $\mathrm{X}$ & $\mathrm{X}$ & $\mathrm{X}$ & $\mathrm{X}$ & $\mathrm{X}$ & $\mathrm{X}$ & $\mathrm{X}$ \\
\hline Descrição de cargos & $\mathrm{X}$ & $\mathrm{X}$ & $\mathrm{X}$ & $\mathrm{X}$ & $\mathrm{X}$ & $\mathrm{X}$ & $\mathrm{X}$ \\
\hline Avaliação de Desempenho & $\mathrm{X}$ & $\mathrm{X}$ & $\mathrm{X}$ & $\mathrm{X}$ & $\mathrm{X}$ & $\mathrm{X}$ & $\mathrm{X}$ \\
\hline Remuneração & - & - & - & - & - & - & - \\
\hline Incentivos & $\mathrm{X}$ & $\mathrm{X}$ & $\mathrm{X}$ & $\mathrm{X}$ & $\mathrm{X}$ & $\mathrm{X}$ & $\mathrm{X}$ \\
\hline Benefícios & - & - & - & - & - & - & - \\
\hline Treinamentos & - & - & - & - & - & - & - \\
\hline Desenvolvimento de carreiras & - & - & - & - & - & - & - \\
\hline Qualidade de vida no trabalho & - & - & - & - & - & - & - \\
\hline Banco de dados & $\mathrm{X}$ & $\mathrm{X}$ & $\mathrm{X}$ & $\mathrm{X}$ & $\mathrm{X}$ & $\mathrm{X}$ & $\mathrm{X}$ \\
\hline Sistema de informação & $\mathrm{X}$ & $\mathrm{X}$ & $\mathrm{X}$ & $\mathrm{X}$ & $\mathrm{X}$ & $\mathrm{X}$ & $\mathrm{X}$ \\
\hline
\end{tabular}

Fonte: dados da pesquisa (2017)

Com base no que os autores da área de gestão de pessoas citam como o conjunto de práticas a serem adotadas, no contexto analisado percebeu-se a limitação no uso de algumas técnicas como: seleção de pessoas, descrição dos cargos, avaliação de desempenho, práticas de incentivos, banco de dados e sistema de informação em gestão de pessoas.

A ausência de práticas de seleção de pessoas para assumirem as funções nas empresas faz com que esse processo se torne moroso e dificulta a escolha do profissional qualificado para o cargo (PEREIRA, 2014). Assim indicam-se alternativas como entrevistas preliminares, inventário biográfico (análise do curriculum), aplicação de testes que revelem aptidões, entrevistas em profundidade capazes de evidenciar capacidades desejáveis, identificação do desempenho futuro e escolha final por parte dos gestores (BOHLANDER E SNELL, 2010). O uso dessas técnicas pelas propriedades rurais no ato da seleção tornam mais confiável e eficaz o processo de contratação de funcionários.

Outra a prática não adotada é a descrição de cargos, a qual uma vez usada, facilita o entendimento na execução das tarefas cotidianas, além de servir como base para construção de outras práticas de gestão de pessoas, por exemplo, a própria seleção de pessoas e a avaliação de desempenho. Nesse quesito, Gil (2011) destaca que descrever cargos contribui para expor de 
forma ordenada as tarefas ou atribuições de um cargo por detalhar o que o ocupante do cargo faz, como faz por que faz. Essa descrição se faz importante principalmente na contração de um novo funcionário, pois serve como manual e facilita seu desempenho inicial, além de demonstrar para os antigos quais são suas obrigações e deveres.

Quanto a avaliação de desempenho, foi constatado que algumas propriedades rurais embora adotem essa prática, utilizam instrumentos limitados para avaliar os conhecimentos, habilidades e atitudes de seus funcionários, assim insuficientes para analisar suas competências e remunerar de forma justa. A ausência de técnicas adequadas torna falho o processo, o qual segundo Bohlander e Snell (2010) permite recompensar e avaliar os funcionários de acordo com suas capacidades e, para Chiavenato (2010) permite aprimorar desempenho profissional (CHIAVENATO, 2010).

Constatou-se ainda que alguns casos analisados não fornecem incentivos aos funcionários, o que pode afetar a produtividade, uma vez que o incentivo é uma forma de motivá-los. Isso vai ao encontro da afirmação de Bohlander e Snell (2009) que percebem os programas de incentivo como forma de criar um ambiente favorável para o desempenho e sucesso da empresa. Incentivos podem ser vinculados a compensações na forma de remuneração, pode ocorrer de forma individual ou grupal. Além da bonificação anual na safra, os casos analisados poderiam fornecer incentivos como: distribuição de prêmios monetários e não monetários, participação nos resultados, pagamento de previdência privada, distribuição de lucros (MARRAS, 2005; PERREIRA, 2014).

Por fim, outra prática não adotada é o banco de dados e sistema de informação em gestão de pessoas, o que denota ausência no armazenamento de informações sobre seu quadro de pessoal, suas práticas, cargos ocupados, resultados de avaliações e quanto à possibilidade de fazerem carreira no empreendimento rural. Práticas essas, conforme Bohlander e Snell (2010) tornam a gestão de pessoas mais efetiva e podem facilitar a rotina dos gestores das propriedades rurais investigadas por contribuir no processo decisório nessa área. A não utilização dessas práticas pode afetar negativamente a gestão das propriedades rurais no que se refere ao capital humano, uma vez que a adequada gestão de pessoas contribui para a organização a alcançar seus objetivos e manutenção da competitividade.

\subsection{Percepção sobre a importância das práticas de gestão de pessoas}


Além de o estudo evidenciar as dificuldades na aplicação das práticas de gestão de pessoas, também captou a percepção quanto à importância das mesmas por parte dos produtores rurais, a qual está mostrada no quadro 6.

Na quantificação dessa percepção, os valores foram considerando nota de 0 a 10 , sendo a nota 0 considerada pouco importante e a nota 10 muito importante.

Quadro 6- Importância das práticas de gestão de pessoas nas propriedades rurais

\begin{tabular}{|c|c|c|c|c|c|c|c|}
\hline \multirow{2}{*}{$\begin{array}{c}\text { Práticas de gestão } \\
\text { de pessoas }\end{array}$} & \multicolumn{7}{c|}{ Propriedades Rurais: Notas atribuídas de 0 a 10 } \\
\cline { 2 - 9 } & $\mathbf{A}$ & $\mathbf{B}$ & $\mathbf{C}$ & $\mathbf{D}$ & $\mathbf{E}$ & $\mathbf{F}$ & $\mathbf{G}$ \\
\hline Recrutamento & 5 & $\mathbf{1 0}$ & $\mathbf{9}$ & $\mathbf{7}$ & $\mathbf{7}$ & $\mathbf{6}$ & $\mathbf{9}$ \\
\hline Seleção & 5 & $\mathbf{1 0}$ & $\mathbf{9}$ & $\mathbf{7}$ & $\mathbf{6}$ & $\mathbf{6}$ & $\mathbf{9}$ \\
\hline $\begin{array}{c}\text { Descrição de } \\
\text { cargos }\end{array}$ & 4 & $\mathbf{8}$ & $\mathbf{9}$ & $\mathbf{6}$ & $\mathbf{6}$ & $\mathbf{6}$ & $\mathbf{9}$ \\
\hline $\begin{array}{c}\text { Avaliação de } \\
\text { desempenho }\end{array}$ & 5 & $\mathbf{8}$ & $\mathbf{9}$ & $\mathbf{6}$ & $\mathbf{5}$ & $\mathbf{5}$ & $\mathbf{9}$ \\
\hline Remuneração & 5 & $\mathbf{8}$ & $\mathbf{1 0}$ & $\mathbf{8}$ & $\mathbf{7}$ & $\mathbf{8}$ & $\mathbf{9}$ \\
\hline Incentivo & 5 & $\mathbf{7}$ & $\mathbf{9}$ & $\mathbf{7}$ & $\mathbf{7}$ & $\mathbf{8}$ & $\mathbf{9}$ \\
\hline Benefícios & 6 & $\mathbf{9}$ & $\mathbf{1 0}$ & 7 & 6 & 8 & $\mathbf{9}$ \\
\hline Treinamento & 5 & $\mathbf{8}$ & $\mathbf{1 0}$ & 7 & 7 & 7 & $\mathbf{9}$ \\
\hline $\begin{array}{c}\text { Desenvolvimento } \\
\text { de carreira }\end{array}$ & 5 & $\mathbf{8}$ & $\mathbf{9}$ & 6 & 6 & 5 & $\mathbf{8}$ \\
\hline $\begin{array}{c}\text { Qualidade de vida } \\
\text { no trabalho }\end{array}$ & 8 & $\mathbf{9}$ & $\mathbf{1 0}$ & 7 & 7 & 6 & $\mathbf{1 0}$ \\
\hline $\begin{array}{c}\text { Sistema de } \\
\text { informação }\end{array}$ & 4 & $\mathbf{8}$ & $\mathbf{1 0}$ & - & 6 & 6 & $\mathbf{9}$ \\
\hline Banco de Dados & 5 & $\mathbf{9}$ & $\mathbf{9}$ & 6 & 7 & 6 & $\mathbf{1 0}$ \\
\hline
\end{tabular}

Fonte: dados da pesquisa (2017)

Ao observar a notas atribuídas pelas propriedades rurais B, C e G entre 8 e 9, constatase que essas percebem como importantes as práticas de gestão de pessoas. Já as propriedades rurais A e E, diferente dos casos anteriores, atribuíram menor importância e, consequentemente as notas foram entre 4 a 7 . Ao contrário das demais, a propriedade D destaca a importância de somente uma: a prática de remuneração com nota 8 , já a propriedade $\mathrm{F}$ percebe como importantes as práticas de remuneração e incentivos, ambas com nota 8.

As propriedades rurais atuam num cenário que requer o uso intensivo de tecnologias, com isso seus gestores precisam direcionar esforços na adoção de práticas de gestão de pessoas, o que permite desenvolver um capital intelectual capaz de incorporar o potencial tecnológico ao dispor da agricultura, haja vista que, de acordo com Salomão (2017) a tecnologia toma espaço nesse contexto e isso deve ser considerado.

\section{CONCLUSÃO}


Nas propriedades rurais analisadas, os resultados sugerem que elas possuem conhecimento das práticas de gestão de pessoas, tanto que algumas as utilizam e outras têm interesse em conhecerem melhor e aplicar. Quanto ao foco central da pesquisa de identificar as práticas de gestão de pessoas adotadas nas propriedades produtoras de grãos no Núcleo Oeste em Mato Grosso, constatou-se que todas adotam práticas tais como: recrutamento e seleção interna e externa, remuneração, incentivos e benefícios, treinamento e qualidade de vida no trabalho. A adoção de tais práticas sinaliza que as propriedades rurais tem certa atenção com a área de gestão de pessoas, não somente para a contratação de profissionais, mas também com a sua permanência para que entreguem resultados positivos, e ao mesmo tempo sintam-se satisfeitos com o trabalho realizado.

Porém, mesmo desenvolvendo algumas ações, os casos investigados ainda encontram dificuldades na adoção de determinadas práticas de gestão de pessoas. Tal dificuldade está relacionada, na opinião dos seus gestores, com a dificuldade de mensurar resultados pela demanda de tempo e investimentos na inserção de novos processos, bem como pela falta de profissional especializado para desenvolver essas práticas. Esse cenário indica a necessidade de melhor estruturação da área de gestão de pessoas nesses empreendimentos, especialmente num momento em que as pessoas passam a ser percebidas como um elemento estratégico dentro do empreendimento, ou seja, são consideradas como parceiras e não mais como mero recurso a ser utilizado no processo produtivo.

No que se refere a percepção dos produtores rurais sobre a importância das práticas de gestão de pessoas, observou-se certa variação nesse quesito, uma vez que dos sete casos analisados, três deles atribuíram maiores notas (entre 8 e 10), para dois casos a importância foi menor (notas de 4 a 7) e, um dos casos considerou importante somente a prática de remuneração (nota 8) e, para outro a relevância foi atribuída às práticas de remuneração e incentivos (ambas com nota 8), o que indica variação quanto a importância percebida sobre tais práticas nesse contexto.

No entanto, mesmo alguns casos percebendo a importância e adotando determinadas práticas, deixam de usar outras técnicas na área, evidenciando uma descontinuidade no processo de gestão de pessoas como um todo, o que impacta nos resultados finais. Nesse sentido, observou-se que, enquanto uma propriedade rural adota práticas de seleção de pessoas, descrição de cargo, avaliação de desempenho, benefícios, desenvolvimento de carreira, banco de dados e sistema de informação, outra não utiliza as práticas de seleção e avaliação de desempenho e uma terceira propriedade não faz uso de banco de dados e sistema de informação 


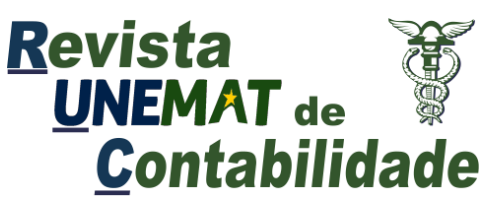

v. 8, n. 16,2019

em gestão de pessoas. Tal variação pode ser atribuída, além das dificuldades supracitadas, à percepção distinta dos gestores que ainda não vislumbram os efeitos positivos das práticas de gestão de pessoas em seu contexto. Um gestor com visão estratégica na área de gestão pessoas perceberá as pessoas como parceiras e, assim buscará envolvimento de todos, e isso passa pela adoção de práticas de gestão de pessoal, as quais compreendem os processos de agregar pessoas, aplicar pessoas, recompensar pessoas, desenvolver pessoas, de manter pessoas e monitorar pessoas.

A contribuição prática do estudo para os gestores rurais, e demais profissionais ligados a gestão de pessoas no âmbito das propriedades rurais, se dá por mostrar a aplicabilidade e necessidade de tais práticas no contexto agrícola, embora tenham surgidos em ambientes com características diferentes do trabalho rural, são necessárias. A não adoção dessas práticas pode impactar os resultados de tais empreendimentos, uma vez as pessoas tanto nas propriedades rurais, como nos demais tipos de organizações são o principal ativo e, portanto, fazem a diferença quando adequadamente gerenciadas.

Como já mencionado, embora pertinente, o tema proposto no ambiente analisado ainda é pouco discutido, o que gerou dificuldades em encontrar materiais relacionados à gestão de pessoas no âmbito das propriedades rurais, o que constituiu uma limitação à realização do estudo uma vez que não se teve parâmetros baseados em locais com características similares para estabelecer comparativo. Considerando essa limitação e o fato do estudo abordar somente alguns casos, sugere-se que pesquisas futuras façam uma abordagem mais robusta envolvendo escopo maior de propriedades rurais, o que possibilitará inferências mais gerais, não limitadas a um pequeno grupo de unidades de produção agrícola.

\begin{abstract}
Personnel management is the function that refers to the management of people and the assignment of tasks in an organization and for that, it comprises a set of practices that aim at the adequacy of the individuals to the work environment to carry out the activities over time. Given the lack of studies on people management practices on rural properties, it was considered relevant to investigate them in this context. With this perspective, the objective was to identify the practices of people management adopted in the rural properties producing grains in the West Nucleus in Mato Grosso. The study based on qualitative data collected in seven medium and large rural properties through a semi - structured interview elaborated from categories of analysis extracted from the literature on the subject. It was then assumed that managing people comprises six processes: aggregating people, applying people, rewarding people, developing people, keeping people, and monitoring people. The results show that all the analyzed sites adopt people management practices, but not in their totality and in a limited way, and not all rural producers perceive the practices of this area as important. In view of this reality, greater attention is drawn to this issue, which directly affects organizational performance and results.
\end{abstract}


Keywords: People management. Practices. Rural developments. Management of rural properties.

\section{REFERÊNCIAS}

AMORIM, Ferreira Gonçalves Nobre Tânia. In: CALLADO, C. A.A. (OR). Agronegócio. 2 ed. São Paulo: Atlas, 2011, p. 30-47.

ARAÚJO J., Massilon. Fundamentos de agronegócio. 2. eEd. São Paulo: atlas, 2005.

BOHLANDER, George; SNELL, Scott. Administração de Recursos humanos. 14 ed. São Paulo: Cengage Learnig, 2010.

BRASIL. Lei no 8.629/1993 de 25 de fevereiro de 1993. Dispõe sobre a regulamentação dos dispositivos constitucionais relativos à reforma agrária. Disponível em:<http://www.planalto.gov.br/ccivil_03/leis/18629.htm>. Acesso em 02 maio 2018.

CAIRES, José Carlos. A Gestão de Pessoas no Agronegócio. Disponível em $<$ http://www.agronline.com.br/artigos/artigo.php?id=330\&pg=2\&n=2> Acesso em 15 Jun. 2017.

CALLADO, Antônio André Cunha. Agronegócio. 3. ed. São Paulo: Atlas, 2011.

CHIAVENATO, Idalberto. Gestão de Pessoas: Enfoque nos papéis profissionais. São Paulo: Atlas, 2011.

CHIAVENATO, Idalberto. Gestão de pessoas: o novo papel dos recursos humanos nas organizações. 2 ed. Rio de Janeiro: Elsevier, 2004.

CODA, Roberto. Competências Comportamentais: Como mapear e desenvolver competências pessoais no trabalho. São Paulo: Atlas, 2016.

DUTRA, Joel Souza. Gestão de pessoas: modelo, processos, tendências e perspectivas. 2 eds. São Paulo: Atlas, 2002.

FERNANDES, Bruno Rocha. Gestão Estratégica de Pessoas com foco em competências. $6^{\text {a }}$ tiragem. Rio de Janeiro: Elsevier, 2013.

FRANÇA, Ana Cristina Limongi. Práticas de Recursos Humanos: Conceito, Ferramentas e Procedimentos. São Paulo: Atlas, 2011.

GIL, Antônio Calos. Como elaborar projetos de pesquisa. 4. ed. São Paulo: Atlas, 2010.

GRAMIGNA, Maria Rita. Gestão por competências: Ferramentas para avaliar e mapear perfis. Rio de Janeiro: Alta Books, 2017.

GRAY, D. I.; PARKER, W. J.; KEMP, E. Farm management research: a discussion of some of the important issues. Journal of International Farm Management, v. 5, n. 1, p. 1-24, 2009.

INSTITUTO BRASILEIRO DE GEOGRAFIA E ESTATÍSTICA (IBGE). IBGE prevê safra de grãos 21,8\% maior que a de 2016: Safra brasileira deve chegar a 224, 2 milhões de toneladas. 2017. Disponível em: <http://g1.globo.com/economia/agronegocios/noticia/ibgepreve-safra-de-graos-218- maior-que-a-de-2016.ghtml>. Acesso em 13 Mar. 2017. 
KAY, Ronald D.; EDWARDS, Willian M.; DUFFY, Patrícia A. Gestão de propriedades rurais. 7 ed. Porto Alegre: AMGH, 2014.

LEITNER, Camyla Piran Stiegler. Estratégias de operações de propriedades produtoras de grãos do núcleo oeste de Mato Grosso. 2015. 212 f. Tese (Doutorado em Engenharia de Produção) - Programa de Pós-Graduação em Engenharia de Produção. Universidade Federal de São Carlos, São Carlos, 2015.

MARRAS, Jean Pierre. Administração de Recursos humanos: do operacional ao estratégico. 3 ed. São Paulo: Futura, 2005.

PEREIRA, Maria Cecília Bastos. RH essencial: Gestão estratégica de pessoas e competências. São Paulo: Saraiva, 2014.

PRODANOV, Cleber Cristiano; FREITAS, Enani Cesar. Metodologia do trabalho cientifico: Métodos e Técnica da Pesquisa e do Trabalho Acadêmico.2 ed. Rio Grande do Sul: Feevale: 2013.

REUTERS, Brasil. PIB do agronegócio sobe 4, $48 \%$ em 2016 com força do setor agrícola. 2017. Disponível: < http://br.reuters.com/article/domesticNews/idBRKBN1722EE-OBRDN>. Acesso em 13 Jun. de 2017.

SALOMÃO, Raphael. Agronegócio sustenta alta do PIB, mas cenário atual ainda exige cautela. Revista Globo Rural. 01 Jun. 2017. Disponível em: $<$ https://revistagloborural.globo.com/ Noticias/Agricultura/noticia/2017/06/agronegocio-sustenta-alta-do-pib-mas-cenarioatualainda-exige-cautela.html>. Acesso em 05 Maio 2018.

SZNITOWSKI, A. M. Uma análise sobre a capacidade absortiva em unidades de produção de soja no Estado de Mato Grosso (Brasil). 2017. 194 f. Tese (Doutorado em Administração) - Universidade do Vale do Rio dos Sinos - UNISINOS. São Leopoldo-RS, 2017. 